\title{
Influence of HLA on clinical and analytical features of pediatric celiac disease
}

\author{
Eva Martínez-Ojinaga', Marta Fernández-Prieto², Manuel Molina'', Isabel Polanco' ${ }^{1}$ Elena Urcelay ${ }^{2}$ and \\ Concepción Núñez ${ }^{2^{*}}$ (D)
}

\begin{abstract}
Background: Celiac disease (CD) is triggered by gluten and related prolamines in genetically susceptible individuals. We aimed to investigate the influence of HLA-DQ genotypes in clinical, serological and histological features related to CD.

Methods: A retrospective observational study was performed including 463 Spanish patients with biopsy-proven CD. Clinical, serological, histological and HLA-DQ genetic data were collected from each participant. The presence of a family history of CD was also considered. Bivariate (chi-square tests or the Fisher's exact test) and multivariate (logistic regression after adjusting for age and sex) analyses were performed to assess the association between clinical and laboratory parameters with HLA-DQ.
\end{abstract}

Results: A predominance of females (62\%), classical clinical presentation (86\%) and positive anti-transglutaminase 2/endomysium antibodies (99\%) was observed in our sample, with a mean age at onset of $2.6 \pm 0.1$ years. Five percent of our patients were first-degree relatives of subjects with CD, with HLA-DQ genetics showing increased homozygosity of HLA-DQ2.5 $(p=0.03)$ and HLA-DQ8 $(p=0.09)$. In the non-CD family history group, an association between delayed disease onset and HLA-DQ8 carriage was observed $(p<0.001)$, besides an influence of HLA$D Q B 1^{*} 02$ gene dosage on clinical presentation and severity of histological damage (after adjusting for age and sex, $p=0.05$ and $p=0.02$, respectively) and a trend towards presence of specific antibodies $(p=0.09)$. These associations could not be evaluated properly in the group of patients with affected first-degree relatives due to the small sample size.

Conclusions: $\mathrm{HLA}-\mathrm{DQ}$ genotypic frequencies differ slightly between $C D$ patients depending on their family history of $C D$. In patients lacking CD first-degree relatives, carriage of HLA-DQ2.5 with double dose of HLA-DQB1*02 seems to be associated with classical clinical presentation and more severe histological damage.

Keywords: HLA-DQ, Clinical symptoms, Serology, Atrophy, Diagnosis

\section{Background}

HLA-DQ2.5 and HLA-DQ8 heterodimeric receptors are considered necessary to develop celiac disease (CD), a systemic disorder characterized by the enteropathy triggered after gluten or related prolamines ingestion [1]. This confers HLA-DQ genotyping a very high negative predictive value for $\mathrm{CD}$ diagnosis, making this practice very useful to help clinicians to discard $\mathrm{CD}[2,3]$.

\footnotetext{
* Correspondence: conchita.npardo@gmail.com

${ }^{2}$ Laboratorio de investigación en Genética de enfermedades complejas, Instituto de Investigación Sanitaria del Hospital Clínico San Carlos (IdISSC), C/ Profesor Martín Lagos s/n 28040, Madrid, Spain

Full list of author information is available at the end of the article
}

HLA-DQ receptors are encoded by $H L A-D Q A 1$ ( $\alpha$ chain) and $H L A-D Q B 1$ ( $\beta$ chain) genes. Specifically, $H L A-$ $D Q A 1 * 05$ and $H L A-D Q B 1 * 02$ encode the HLA-DQ2.5 receptor and HLA-DQA1*03 and HLA-DQB1*03:02 encode HLA-DQ8. Around $90-96 \%$ of CD patients carry HLADQ2.5 and almost all the remainders carry HLA-DQ8 [4]. Both are involved in $\mathrm{CD}$ pathogenesis. They appear on the surface of antigen presenting cells and show high affinity by deamidated gluten-derived peptides, which bind and present to CD4 T cells located in the lamina propia, initiating the inflammatory cascade that is characteristic of $\mathrm{CD}$ [5]. As a consequence, specific antibodies, mainly antitransglutaminase 2 (TG2) and anti-endomysium (EMA)

(c) The Author(s). 2019 Open Access This article is distributed under the terms of the Creative Commons Attribution 4.0 International License (http://creativecommons.org/licenses/by/4.0/), which permits unrestricted use, distribution, and 
antibodies, are produced, both directed against TG2, which is responsible for gluten deamidation and becomes the main autoantigen of $\mathrm{CD}$. But the capital change involves the intestinal damage that usually includes villous atrophy and is accompanied by clinical manifestations in most cases.

The binding properties to gluten-derived peptides and the capacity to elicit an immunological response depends on the specific HLA-DQ molecules present in each individual, existing also a dosage effect [6-8]. HLA-DQ2.5 can bind the largest repertoire of immunodominant gluten peptides and presents the highest ability to form stable complexes. Thus, individuals carrying the HLA-DQ2.5 heterodimer show the highest risk to develop $C D$, especially when bearing two $H L A-D Q B 1 * 02$ alleles (double dose). The risk decreases in individuals with HLA-DQ8 or only the HLA-DQB1*02 allele (HLADQ2.2 receptor), and is lowest in presence of only $H L A$ $D Q A 1$ "05 (HLA-DQ7.5 receptor). Considering these differences, we hypothesized that HLA-DQ receptors could have a role on the clinical outcome and/or the serological and histological alterations present in each patient. However, little information exists regarding this issue, with some papers relating HLA genetics with some clinical and analytical characteristics but not others [9-14].

In a previous work, we studied the different $\mathrm{CD}$ risk conferred by HLA-DQ genotypes [15]. At this time, we have performed a retrospective observational study to analyze the possible influence of HLA-DQ genotypes on the clinical, analytical and histological manifestations at the onset of $\mathrm{CD}$.

\section{Methods}

\section{Study subjects}

A total of 463 subjects with CD were included, all studied in a previous work [15]. These patients were diagnosed at the Gastroenterology Department of the Hospital La Paz between 1977 and 2011 according to the corresponding valid ESPGHAN criteria [1, 16]. All were children (0-14 years old) with Spanish ancestry.

\section{HLA-DQ genotyping and distribution}

HLA-DQ genotyping was performed using PCR-SSOP (Polymerase Chain Reaction-Sequence Specific Oligonucleotide Probe) for $H L A-D R B 1,-D Q A 1$ and $-D Q B 1$. HLA-DQ data of our CD patients are shown in Table 1.

\section{Clinical and analytical data}

The following variables were extracted after reviewing inpatient and outpatient medical records: 1) sex; 2) age at onset, considered as the first time of reporting the clinical symptoms explained by $C D ; 3)$ clinical manifestations, being classified as classical symptoms (weight
Table 1 HLA-DQ distribution in our celiac disease patients

\begin{tabular}{lll}
\hline HLA-DQ genotype & $\mathrm{N}$ & $\%$ \\
\hline HLA-DQ2.5/DQ2.5 & 54 & 11.7 \\
HLA-DQ2.5/DQ2.2 & 135 & 29.2 \\
HLA-DQ2.5/DQ7.5 & 38 & 8.2 \\
HLA-DQ2.5/DQX & 138 & 29.8 \\
HLA-DQ2.5/DQ8 & 20 & 4.3 \\
HLA-DQ2.2/DQ7.5 & 60 & 13.0 \\
HLA-DQ8/DQ8 & 2 & 0.4 \\
HLA-DQ8/DQ2.2, DQ7.5 or DQX & 8 & 1.7 \\
HLA-DQ2.2/DQX & 7 & 1.5 \\
HLA-DQ7.5/DQX & 1 & 0.2 \\
\hline
\end{tabular}

${ }^{a}$ HLA-DQ2.5 trans; HLA-DQX indicates an haplotype different from HLA-DQ2.5, HLA-DQ8, HLA-DQ2.2 and HLA-DQ7.5

loss, growth retardation, chronic diarrhea, vomiting, hyporexia and abdominal distension) and non-classical symptoms (iron deficiency anemia, oral thrush, dermatitis herpetiformis or subclinical disease in individuals from risk groups such as first-degree relatives with $C D$ or presence of associated conditions); 4) serological data: positive/negative IgA or IgG (in IgA deficient patients) anti-TG2 and/or EMA, and in case of positive anti-TG2, we also considered the antibody level by establishing two groups $(\leq$ or $>10$ times the upper limit of normality); 5) histology, graded following the Marsh-Oberhuber classification [17], with biopsies obtained before using this classification adapted as follows: normal histology as Marsh 0, lymphocytic enteritis as Marsh 1, mild partial atrophy as Marsh 2, moderate partial atrophy as Marsh 3a, intense partial atrophy as Marsh $3 \mathrm{~b}$ and subtotal atrophy as Marsh 3c.

\section{Statistical analysis}

The association between clinical and laboratory parameters, and between each of them and HLA was assessed by chi-square tests or the Fisher's exact test, when appropriate, using $2 \times 2$ contingency tables (bivariate analysis) or by logistic regression after adjusting for age and sex (multivariate analysis). Comparisons related to age at onset were performed by means of the Mann-Whitney $\mathrm{U}$ test or the Kruskal-Wallis test depending on two or more groups were considered, respectively. Two-sided tests were always considered and significant associations were established at $p$ values below 0.05. Analyses were performed with Statcalc (EpiInfo v6) or the statistical package SPSS v24.0.

\section{Results}

Age at onset ranged from 7 months to 14 years in our $463 \mathrm{CD}$ patients, with a mean of $2.6 \pm 0.1$ years. A predominance of females (62\%) and classical clinical 
presentation (86\%) was observed. All but two patients showed positive anti-TG2/EMA serology. Since CD was confirmed in all patients and anti-TG2 and EMA antibodies identify the same antigen but only one of them was determined in some of our patients, we considered both antibodies together and called anti-TG2/EMA positive individuals to those showing either anti-TG2 or EMA positive antibodies. Among the 178 patients with available anti-TG2 level, 97\% were considered positive, the vast majority showing elevated levels (69\%). A severe villous lesion (Marsh 3b or Marsh 3c) was observed in $90 \%$ of the patients, being the majority Marsh 3c.

In a first exploration of the demographic, clinical and analytical variables, early onset was associated with classical clinical presentation: mean age $2.08 \pm 0.09$ years (range 7 months-14 years) in patients with classical symptoms vs. $6.21 \pm 0.43$ years (range 13 months- 14 years) in patients with non-classical presentation $(p<$ 0.001 ); and also with more severe tissue injury: $2.33 \pm$ 0.51 in Marsh 2 (10 subjects), $3.98 \pm 0.70$ in Marsh 3a (29 subjects), $3.01 \pm 0.22$ in Marsh $3 \mathrm{~b}$ (134 subjects) and $2.36 \pm 0.13$ in Marsh 3c (283 subjects) $(p=0.007)$; and with presence of anti-TG2/EMA antibodies: $1.31 \pm 0.12$ vs. $3.27 \pm 0.18$ in subjects with negative and positive antibodies, respectively $(p<0.001)$. Severity of mucosal lesion was also associated with sex, with males showing milder (Marsh 0 to Marsh 3a) mucosal lesions ( $p=$ $0.014)$ independently of age at onset; and with anti-TG2 level $(p=0.013)$, independently of age at onset and sex. To note, only two patients showed Marsh 0 and Marsh 1, both EMA-positive and with clinical and analytical response to the gluten free diet. After gluten challenge, the patient with Marsh 0 showed positive anti-TG2 antibodies and atrophy (Marsh 3b).

Next, we considered the association between clinical and analytical features with the HLA-DQ status.

A family history of CD was observed in $22(4.8 \%)$ of our patients. Their HLA-DQ distribution is shown in Table 2.

Comparison between these HLA-DQ frequencies and the ones observed in the remaining patients showed a nearly significant result: $p=0.067$. Specifically, HLADQ2.5 and HLA-DQ8 homozygosity were notoriously increased in the group of patients with $\mathrm{CD}$ relatives: $27.3 \%$ vs. $10.9 \%(p=0.03)$ and $4.5 \%$ vs. $0.2 \%(p=0.093)$,

Table 2 HLA-DQ distribution in our patients with a family history of celiac disease

\begin{tabular}{ll}
\hline HLA genotype & $\mathrm{N}(\%)$ \\
\hline HLA-DQ2.5/DQ2.5 & $6(27.3)$ \\
HLA-DQ2.5/DQ2.2 & $8(36.4)$ \\
HLA-DQ2.5 /DQX & $7(31.8)$ \\
HLA-DQ8/DQ8 & $1(4.5)$ \\
\hline
\end{tabular}

respectively, although a significant result was only achieved when considering HLA-DQ2.5. These results led us to perform subsequent analyses after stratifying by family history of $C D$.

No significant changes across HLA-DQ genotypes were observed between sexes. Next, we analyzed the influence of HLA-DQ on age at onset. In the group with non-CD family history, we observed a significantly later disease onset in HLA-DQ8 carriers (including HLADQ8/DQ8 and HLA-DQ8/DQ2.5 subjects) when compared to non-HLA-DQ8 carriers: mean age $4.43 \pm 0.66$ years vs. $2.54 \pm 0.11$ years, respectively $(p<0.001)$. In patients with family history of $C D$, we could not evaluate this issue since HLA-DQ8 was only observed in one patient.

Finally, we studied the possible influence of the double $H L A-D Q B 1 * 02$ gene dosage (in HLA-DQ2.5 carriers) on clinical presentation, serology and histological severity (Table 3).

Slight variations in the number of patients depending on the considered variables were present owing to missing data. In the non-CD family history group, the classical clinical presentation was more frequently observed in HLA-DQ2.5 patients with double $H L A-D Q B 1 * 02$ dosage, and the effect depended on age at onset (Table 4).

This genetics was also associated with the severity of histological damage, being this effect not probably affected by age and/or sex. The presence of specific antibodies was increased in presence of two $H L A-D Q B 1 * 02$ alleles, although the effect was only nearly significant. Anti-TG2 levels were not associated with HLA gene dosage. The effect of the HLA on clinical presentation and histological severity was also analyzed adjusting by anti-TG2 titer in the subgroup of patients with available data, but this variable was not acting as a confusing variable (data not shown).

No significant differences were observed in the group of family history, but our results are compromised by the small sample size and the resulting low statistical power.

No differences between HLA-DQ2.5 heterozygous individuals (excluding HLA-DQ2.5/DQ8 subjects) and HLADQ8 carriers were observed regarding any of the considered features (age at onset, clinical presentation, antibodies or histological damage) after adjustment for age.

\section{Discussion}

We have studied, to the best of our knowledge, the largest CD series in relation to HLA and clinical and analytical features. A total of 463 children were considered, with a predominance of girls, early onset and classical clinical presentation, as commonly reported in pediatric series with $C D[14,18-20]$. Also according to the literature, we found that early onset was associated to 
Table $3 \mathrm{HLA}-\mathrm{DQ}$ data in relation to clinical and analytical features stratified by family history in CD

\begin{tabular}{|c|c|c|c|c|c|c|c|c|c|c|c|}
\hline & & \multicolumn{2}{|c|}{$\begin{array}{l}\text { Sex } \\
n=463\end{array}$} & \multicolumn{2}{|c|}{$\begin{array}{l}\text { Clinical Presentation } \\
n=463\end{array}$} & \multicolumn{2}{|c|}{$\begin{array}{l}\text { Histological Damage } \\
n=458\end{array}$} & \multicolumn{2}{|c|}{$\begin{array}{l}\text { Anti-TG2/EMA } \\
n=275\end{array}$} & \multicolumn{2}{|c|}{$\begin{array}{l}\text { Anti-TG2 Levels } \\
n=172\end{array}$} \\
\hline & & M & $\mathrm{F}$ & Classical & Non-Classical & $M 3 b+M 3 c$ & Milder lesion & Positive & Negative & $\geq 100$ & $<100$ \\
\hline \multirow[t]{2}{*}{ Family History } & HLA-DQ2.5 double dose & $\begin{array}{l}10 \\
66.7 \%\end{array}$ & $\begin{array}{l}5 \\
33.3 \%\end{array}$ & $\begin{array}{l}4 \\
28.6 \%\end{array}$ & $\begin{array}{l}10 \\
71.4 \%\end{array}$ & $\begin{array}{l}13 \\
92.9 \%\end{array}$ & $\begin{array}{l}1 \\
7.1 \%\end{array}$ & $\begin{array}{l}12 \\
100 \%\end{array}$ & 0 & $\begin{array}{l}6 \\
75 \%\end{array}$ & $\begin{array}{l}2 \\
25 \%\end{array}$ \\
\hline & Other HLA-DQ & $\begin{array}{l}3 \\
42.9 \%\end{array}$ & $\begin{array}{l}4 \\
57.1 \%\end{array}$ & $\begin{array}{l}3 \\
37.5 \%\end{array}$ & $\begin{array}{l}5 \\
62.5 \%\end{array}$ & $\begin{array}{l}8 \\
100 \%\end{array}$ & 0 & $\begin{array}{l}5 \\
100 \%\end{array}$ & 0 & $\begin{array}{l}3 \\
60 \%\end{array}$ & $\begin{array}{l}2 \\
40 \%\end{array}$ \\
\hline \multirow[t]{2}{*}{ Non-Family History } & $\begin{array}{l}\text { HLA-DQ2.5 } \\
\text { double dose }\end{array}$ & $\begin{array}{l}68 \\
39.1 \%\end{array}$ & $\begin{array}{l}106 \\
60.9 \%\end{array}$ & $\begin{array}{l}162 \\
92.6 \%\end{array}$ & $\begin{array}{l}13 \\
7.4 \%\end{array}$ & $\begin{array}{l}164 \\
94.8 \%\end{array}$ & $\begin{array}{l}9 \\
5.2 \%\end{array}$ & $\begin{array}{l}110 \\
99.1 \%\end{array}$ & $\begin{array}{l}1 \\
0.9 \%\end{array}$ & $\begin{array}{l}43 \\
70.5 \%\end{array}$ & $\begin{array}{l}18 \\
29.5 \%\end{array}$ \\
\hline & Other HLA-DQ & $\begin{array}{l}94 \\
35.2 \%\end{array}$ & $\begin{array}{l}173 \\
64.8 \%\end{array}$ & $\begin{array}{l}229 \\
86.1 \%\end{array}$ & $\begin{array}{l}37 \\
13.9 \%\end{array}$ & $\begin{array}{l}232 \\
88.2 \%\end{array}$ & $\begin{array}{l}31 \\
11.8 \%\end{array}$ & $\begin{array}{l}153 \\
93.3 \%\end{array}$ & $\begin{array}{l}11 \\
6.7 \%\end{array}$ & $\begin{array}{l}67 \\
68.4 \%\end{array}$ & $\begin{array}{l}31 \\
31.6 \%\end{array}$ \\
\hline
\end{tabular}

classical symptoms. It is well-known that a classical presentation is the predominant clinical form in children, especially in those under 3 years old [21]. A higher frequency of the non-classical clinical presentation was observed in patients with a family history of $\mathrm{CD}$. This observation must be cautiously interpreted, because in absence of clinical symptoms suggestive of $C D$, the screening for this disease is performed in individuals belonging to risk groups, which include individuals having first-degree relatives with CD. However, it has been previously observed that $C D$ patients with affected firstdegree relatives developed $\mathrm{CD}$ after years of negative serological testing, being all HLA-DQ2.5 positive and clinically silent for CD [22].

We found a lower percentage of positive serology in children under 2-3 years old, as well as a positive association of anti-TG2 levels and mucosal severity. Both observations are already well-known $[12,23]$ and the last one has indeed been used to avoid biopsy in those children with high antibody titers according to the most recent ESPGHAN diagnostic guidelines [1]. In addition, we found more severe histological damage at earlier onset, as also previously reported [24], and in females.

When considering the influence of HLA-DQ on CD features, the first notorious observation was the higher frequency of HLA-DQ2.5 and HLA-DQ8 homozygotes in individuals with first-degree relatives with $\mathrm{CD}$. This

Table 4 Association between $H L A-D Q B 1^{*} 02$ gene dosage and clinical and analytical features

\begin{tabular}{|c|c|c|c|c|}
\hline & \multicolumn{2}{|l|}{ Bivariate analysis } & \multicolumn{2}{|l|}{ Multivariate analysis } \\
\hline & OR (Cl 95\%) & $p$ & $\mathrm{OR}(\mathrm{Cl} 95 \%)$ & $p$ \\
\hline Clinical presentation $^{a}$ & $2.01(1.04-3.91)$ & 0.04 & $2.31(1.01-5.32)^{*}$ & $0.05^{*}$ \\
\hline Histological severity ${ }^{\mathrm{b}}$ & $2.43(1.13-5.26)$ & 0.02 & $2.54(1.16-5.52)^{* *}$ & $0.02^{*}$ \\
\hline Serology ${ }^{c}$ & $6.64(0.84-52.7)$ & 0.07 & $6.09(0.74-49.87)^{* *}$ & $0.09^{* *}$ \\
\hline Anti-TG2 level ${ }^{d}$ & $0.91(0.45-1.81)$ & 0.78 & $0.91(0.45-1.61)^{* *}$ & $0.80^{* *}$ \\
\hline
\end{tabular}

*corrected by age at onset. When corrected by sex and age: $\mathrm{OR}(95 \% \mathrm{Cl})=2.2$ $(0.95-5.10) \cdot p=0.066$

** corrected by age at onset and sex

ORs are referred to ${ }^{a}$ classical vs. non-classical presentation; ${ }^{\mathrm{b}}$ Marsh $3 \mathrm{~b} /$ Marsh $3 c$ vs. others; ${ }^{C}$ positive vs. negative anti-TG2/EMA, excluding IgA deficient patients; ${ }^{\mathrm{d}}$ anti-TG $2 \leq 10$ vs. $>10$ the upper limit of normality could be an expected result considering the high heritability of CD and that HLA accounts for around $40 \%$ of the total genetic risk.

The observed different genetic background depending on the family history of $\mathrm{CD}$ forced the subsequent analyses based on the role of HLA on clinical and analytical features, to be performed in the two groups separately. The most numerous group lacked CD familiarity. In this case, we observed that a later disease onset was present in HLA-DQ8 carriers, including those who were HLADQ2.5/DQ8. Although, to our knowledge, this is the first report of this effect, it is noteworthy to mention that Liu et al. [11] studied prospectively CD onset in children with HLA-DQ2.5 or HLA-DQ8 and observed that HLA-DQ2.5 homozygous subjects showed the earliest $\mathrm{CD}$ onset, being the other groups studied: HLA-DQ2.5/DQ8, HLA-DQ8/ DQ8 and HLA-DQ8/non-HLA risk. Striking observations also emerged when studying the differential effect of HLA-DQ2.5 with double dose. The two groups established to make these comparisons (HLA-DQ2.5 carriers with two $H L A-D Q B 1 * 02$ alleles vs. the remaining patients) constitute the largest ones and give the most statistical power. We found that a classical clinical presentation was increased in carriers of HLA-DQ2.5 with double HLA$D Q B 1 * 02$ dose. A similar effect was described by Zubillaga et al. [14] and Piccinni et al. [13], the last ones showing that atypical or silent/latent $\mathrm{CD}$ was more frequent in patients with low risk genetics. We also observed an association of HLA-DQ2.5 with double dose with severity of mucosal lesion, concordantly with previous studies in children and adults $[9,12]$. The association with the presence of anti-TG2/EMA antibodies was only nearly significant, nevertheless, similar results were previously described in adults [25]. We did not find association of HLA-DQ with anti-TG2 levels, which has been also reported [11, 12, 26]. This could be due to the way of analyzing data, since we considered only two anti-TG2 levels: < or $\geq 10$ times the upper limit of normality, because that was the only information available for most of our patients. Further analyses using the precise values of anti-TG2 antibodies could yield different results and need to be considered. 
Only 22 individuals showed affected relatives and therefore the HLA influence could not be evaluated properly in this subgroup. However, it seems that HLADQ2.5 with double dose does not lead to a classical clinical presentation, which would differentiate both groups. Regarding the remaining considered features, it is possible that similar results exist. In a previous work analyzing $144 \mathrm{CD}$ adults with $\mathrm{CD}$ family history, Karinen et al. observed a gene dosage effect of $H L A-D Q B 1 * 02$ on the grading of villous atrophy and age at onset [10].

$\mathrm{CD}$ is a highly heterogeneous disorder. When considering clinical manifestations, it ranges from a subclinical disease to a wide variety of signs and symptoms. Similarly, all the possible range of values is observed when looking at specific antibody levels. The intestinal damage, considered the hallmark of $\mathrm{CD}$, can also vary from intraepithelial lymphocytosis to total atrophy. In this work, we demonstrate that HLA-DQ gene dosage is contributing to the observed heterogeneity. The highest genetic risk, which is conferred by the presence of the HLA-DQ2.5 heterodimer with two copies of HLA$D Q B 1 * 02$ is associated to an earlier onset, a classical clinical presentation and a severe histological damage. It could also have influence on the presence of antibodies targeting TG2. The correlation between some of those parameters was previously known, and with our work, HLA becomes part of the picture. This issue has been largely suspected, but many apparent discrepancies are present among previous studies, mostly influenced by the small sample sizes previously considered, which may contribute to obtain false negative results [27]. Besides our sample size, other strength of our study is that all patients were diagnosed in the same center and revised by the same physician. Therefore no bias by different clinical practice exists.

Further studies are necessary to ascertain the impact of our observations in patients with a family history of $\mathrm{CD}$ and in adults, although looking at previous reports, it is possible that these associations are also present.

It may be that differences also exist between $\mathrm{CD}$ patients with HLA-DQ2.5 with single dose and those carrying HLA-DQ8 or lower risk HLA genotypes. The frequency of patients with these genetics is very low, and a multicenter study would be necessary to address this issue.

\section{Conclusions}

The current use of HLA genotyping in clinical practice relies on its high negative predictive value. It is recommended to test HLA in patients with an uncertain diagnosis, as those with negative $\mathrm{CD}$-specific antibodies and/ or mild histological changes in small intestine. Based on the associations here found between double dose HLADQ2.5 and some clinical and analytical parameters, most probably high risk HLA-DQ genotypes will not be present in those subjects, which should be considered by physicians. Our study also suggests that patients with a family history of $C D$ need a special consideration, since HLA-DQ status show slight variations.

HLA-DQ genotypic frequencies differ slightly between $\mathrm{CD}$ patients depending on their family history of $\mathrm{CD}$. In patients lacking $C D$ first-degree relatives, carriage of HLA-DQ2.5 with double dose of $H L A-D Q B 1 * 02$ seems to be associated with classical clinical presentation and more severe histological damage.

\section{Abbreviations}

CD: Celiac disease; EMA: Anti-endomysium antibodies; PCR-SSOP: Polymerase Chain Reaction-Sequence Specific Oligonucleotide Probe;

TG2: Transglutaminase 2

\section{Acknowledgements}

We are grateful to Dr. Emilio Gómez de la Concha, Dr. Miguel Fernández Arquero and Carmen Martínez.

\section{Author's contributions}

$\mathrm{CN}$ conceived and designed the study, analyzed and interpreted the data and wrote the paper. EMO collected, analyzed and interpreted the data and wrote the paper. IP collected and interpreted the data. MFP, MM and EU analyzed and interpreted the data. All authors approved the final manuscript as submitted and agree to be accountable for all aspects of the work.

\section{Funding}

Concepción Núñez is supported by a research grant from "Fondo de Investigaciones Sanitarias, Instituto de Salud Carlos III (AES 2015) PI15/01186Fondo Europeo de Desarrollo Regional (FEDER)". The funding body had no role in the design of the study and collection, analysis, and interpretation of data and in writing the manuscript.

\section{Availability of data and materials}

The datasets used and analyzed during the current study are available from the corresponding author on reasonable request.

\section{Ethics approval and consent to participate}

The study was conducted in accordance with the Declaration of Helsinki and was approved by the Ethics Committee of the Hospital La Paz.

\section{Consent for publication}

Not applicable.

\section{Competing interests}

The authors declare that they have no competing interest.

\section{Author details}

${ }^{1}$ Servicio de Gastroenterología y Nutrición Pediátrica, Hospital Universitario La Paz, Madrid, Spain. ${ }^{2}$ Laboratorio de investigación en Genética de enfermedades complejas, Instituto de Investigación Sanitaria del Hospital Clínico San Carlos (IdISSC), C/ Profesor Martín Lagos s/n 28040, Madrid, Spain.

Received: 5 October 2018 Accepted: 6 June 2019

Published online: 13 June 2019

References

1. Husby S, Koletzko S, Korponay-Szabo IR, Mearin ML, Phillips A, Shamir R, et al. European Society for Pediatric Gastroenterology, hepatology, and nutrition guidelines for the diagnosis of coeliac disease. J Pediatr Gastroenterol Nutr. 2012;54(1):136-60.

2. Diaz-Redondo A, Miranda-Bautista J, Garcia-Lledo J, Gisbert JP, Menchen L. The potential usefulness of human leukocyte antigen typing for celiac disease screening: a systematic review and meta-analysis. Rev Esp Enferm Dig. 2015;107(7):423-9. 
3. Hadithi M, von Blomberg BM, Crusius JB, Bloemena E, Kostense PJ, Meijer JW, et al. Accuracy of serologic tests and HLA-DQ typing for diagnosing celiac disease. Ann Intern Med. 2007;147(5):294-302.

4. Wolters VM, Wijmenga C. Genetic background of celiac disease and its clinical implications. Am J Gastroenterol. 2008;103(1):190-5.

5. Sollid LM, Jabri B. Triggers and drivers of autoimmunity: lessons from coeliac disease. Nat Rev Immunol. 2013;13(4):294-302.

6. Bodd M, Kim CY, Lundin KE, Sollid LM. T-cell response to gluten in patients with HLA-DQ2.2 reveals requirement of peptide-MHC stability in celiac disease. Gastroenterology. 2012;142(3):552-61.

7. Fallang LE, Bergseng E, Hotta K, Berg-Larsen A, Kim CY, Sollid LM. Differences in the risk of celiac disease associated with HLA-DQ2.5 or HLADQ2.2 are related to sustained gluten antigen presentation. Nat Immunol. 2009;10(10):1096-101.

8. Tollefsen S, Arentz-Hansen H, Fleckenstein B, Molberg O, Raki M, Kwok WW, et al. HLA-DQ2 and -DQ8 signatures of gluten T cell epitopes in celiac disease. J Clin Invest. 2006;116(8):2226-36.

9. Jores RD, Frau F, Cucca F, Grazia Clemente M, Orru S, Rais M, et al. HLADQB1*0201 homozygosis predisposes to severe intestinal damage in celiac disease. Scand J Gastroenterol. 2007;42(1):48-53.

10. Karinen H, Karkkainen P, Pihlajamaki J, Janatuinen E, Heikkinen M, Julkunen $R$, et al. Gene dose effect of the DQB1*0201 allele contributes to severity of coeliac disease. Scand J Gastroenterol. 2006:41(2):191-9.

11. Liu E, Lee HS, Aronsson CA, Hagopian WA, Koletzko S, Rewers MJ, et al. Risk of pediatric celiac disease according to HLA haplotype and country. N Engl J Med. 2014;371(1):42-9.

12. Nenna R, Mora B, Megiorni F, Mazzilli MC, Magliocca FM, Tiberti C, et al. $\mathrm{HLA}-\mathrm{DQB} 1^{*} 02$ dose effect on RIA anti-tissue transglutaminase autoantibody levels and clinicopathological expressivity of celiac disease. J Pediatr Gastroenterol Nutr. 2008;47(3):288-92.

13. Piccini B, Vascotto $M$, Serracca L, Luddi A, Margollicci MA, Balestri $P$, et al HLA-DQ typing in the diagnostic algorithm of celiac disease. Rev Esp Enferm Dig. 2012;104(5):248-54.

14. Zubillaga P, Vidales MC, Zubillaga I, Ormaechea V, Garcia-Urkia N, Vitoria JC. HLA-DQA1 and HLA-DQB1 genetic markers and clinical presentation in celiac disease. J Pediatr Gastroenterol Nutr. 2002;34(5):548-54.

15. Martínez-Ojinaga E, Molina M, Polanco I, Urcelay E, Núñez C. HLA-DQ distribution and risk assessment to suffer from celiac disease in a Spanish center. Rev Esp Enferm Dig. 2018; in press.

16. Revised criteria for diagnosis of coeliac disease. Report of working Group of European Society of Paediatric gastroenterology and nutrition. Arch Dis Child 1990, 65(8):909-911.

17. Oberhuber G, Granditsch G, Vogelsang H. The histopathology of coeliac disease: time for a standardized report scheme for pathologists. Eur J Gastroenterol Hepatol. 1999;11(10):1185-94.

18. Cilleruelo ML, Roman-Riechmann E, Sanchez-Valverde F, Donat E, Manuel-Ramos J, Martin-Orte E, et al. Spanish national registry of celiac disease: incidence and clinical presentation. J Pediatr Gastroenterol Nutr. 2014;59(4):522-6.

19. Llorente-Alonso MJ, Fernandez-Acenero MJ, Sebastian M. Gluten intolerance: sex and age-related features. Can J Gastroenterol. 2006;20(11):719-22.

20. Misak Z, Hojsak I, Jadresin O, Kekez AJ, Abdovic S, Kolacek S. Diagnosis of coeliac disease in children younger than 2 years. J Pediatr Gastroenterol Nutr. 2013;56(2):201-5.

21. Diamanti A, Capriati T, Basso MS, Panetta F, Di Ciommo Laurora VM, Bellucci F, et al. Celiac disease and overweight in children: an update. Nutrients. 2014;6(1):207-20.

22. Pittschieler K, Gentili L, Niederhofer H. Onset of coeliac disease: a prospective longitudinal study. Acta Paediatr. 2003;92(10):1149-52.

23. Mubarak A, Wolters VM, Gerritsen SA, Gmelig-Meyling FH, Ten Kate FJ, Houwen $\mathrm{RH}$. A biopsy is not always necessary to diagnose celiac disease. J Pediatr Gastroenterol Nutr. 2011:52(5):554-7.

24. Vivas S, Ruiz de Morales JM, Fernandez M, Hernando M, Herrero B, Casqueiro J, et al. Age-related clinical, serological, and histopathological features of celiac disease. Am J Gastroenterol. 2008;103(9):2360-5 quiz 2366

25. Thomas HJ, Ahmad T, Rajaguru C, Barnardo M, Warren BF, Jewell DP. Contribution of histological, serological, and genetic factors to the clinical heterogeneity of adult-onset coeliac disease. Scand J Gastroenterol. 2009; 44(9):1076-83.
26. Hoffenberg EJ, MacKenzie T, Barriga KJ, Eisenbarth GS, Bao F, Haas JE, et al. A prospective study of the incidence of childhood celiac disease. J Pediatr. 2003;143(3):308-14.

27. Murray JA, Moore SB, Van Dyke CT, Lahr BD, Dierkhising RA, Zinsmeister AR, et al. HLA DQ gene dosage and risk and severity of celiac disease. Clin Gastroenterol Hepatol. 2007;5(12):1406-12.

\section{Publisher's Note}

Springer Nature remains neutral with regard to jurisdictional claims in published maps and institutional affiliations.
Ready to submit your research? Choose BMC and benefit from:

- fast, convenient online submission

- thorough peer review by experienced researchers in your field

- rapid publication on acceptance

- support for research data, including large and complex data types

- gold Open Access which fosters wider collaboration and increased citations

- maximum visibility for your research: over $100 \mathrm{M}$ website views per year

At BMC, research is always in progress.

Learn more biomedcentral.com/submissions 